\title{
Comparison of foot orthoses made by podiatrists, pedorthists and orthotists regarding plantar pressure reduction in The Netherlands Nick A Guldemond* ${ }^{* 1}$, Pieter Leffers ${ }^{\dagger 2}$, Nicolaas C Schaper ${ }^{3}$, Antal P Sanders ${ }^{4}$, Fred HM Nieman ${ }^{5}$ and Geert HIM Walenkamp ${ }^{\dagger 1}$
}

\begin{abstract}
Address: ${ }^{1}$ Department of Orthopaedic Surgery, University Hospital Maastricht, The Netherlands, ${ }^{2}$ Department of Epidemiology, University Maastricht, The Netherlands, ${ }^{3}$ Department of Rehabilitation Medicine, University Hospital Maastricht, The Netherlands, ${ }^{4}$ Department of Internal Medicine, University Hospital Maastricht, The Netherlands and ${ }^{5}$ Department of Clinical Epidemiology and Medical Technology Assessment, University Hospital Maastricht, The Netherlands

Email: Nick A Guldemond* - ngu@orthop.unimaas.nl; Pieter Leffers - p.leffers@pid.unimaas.nl; Nicolaas C Schaper - nsc@sint.azm.nl; Antal P Sanders - asan@rev.azm.nl; Fred HM Nieman - fni@oazg.azm.nl; Geert HIM Walenkamp - gwa@sort.azm.nl

* Corresponding author †Equal contributors
\end{abstract}

Published: 20 December 2005

BMC Musculoskeletal Disorders 2005, 6:61 doi:10.1 186/147|-2474-6-61
Received: 10 May 2005

Accepted: 20 December 2005

This article is available from: http://www.biomedcentral.com/147I-2474/6/6I

(c) 2005 Guldemond et al; licensee BioMed Central Ltd.

This is an Open Access article distributed under the terms of the Creative Commons Attribution License (http://creativecommons.org/licenses/by/2.0), which permits unrestricted use, distribution, and reproduction in any medium, provided the original work is properly cited.

\begin{abstract}
Background: There is a need for evidence of clinical effectiveness of foot orthosis therapy. This study evaluated the effect of foot orthoses made by ten podiatrists, ten pedorthists and eleven orthotists on plantar pressure and walking convenience for three patients with metatarsalgia. Aims were to assess differences and variability between and within the disciplines. The relationship between the importance of pressure reduction and the effect on peak pressure was also evaluated.

Methods: Each therapist examined all three patients and was asked to rate the 'importance of pressure reduction' through a visual analogue scale. The orthoses were evaluated twice in two sessions while the patient walked on a treadmill. Plantar pressures were recorded with an in-sole measuring system. Patients scored walking convenience per orthosis. The effects of the orthoses on peak pressure reduction were calculated for the whole plantar surface of the forefoot and six regions: big toe and metatarsal one to five.

Results: Within each discipline there was an extensive variation in construction of the orthoses and achieved peak pressure reductions. Pedorthists and orthotists achieved greater maximal peak pressure reductions calculated over the whole forefoot than podiatrists: 960,1020 and $750 \mathrm{kPa}$, respectively $(p<.001)$. This was also true for the effect in the regions with the highest baseline peak pressures and walking convenience rated by patients $A$ and $B$. There was a weak relationship between the 'importance of pressure reduction' and the achieved pressure reduction for orthotists, but no relationship for podiatrists and pedorthotists.
\end{abstract}

Conclusion: The large variation for various aspects of foot orthoses therapy raises questions about a consistent use of concepts for pressures management within the professional groups. 


\section{Background}

A variety of foot impairments such as rheumatoid arthritis and diabetes are associated with elevated plantar forefoot peak pressures and metatarsalgia[1]. Reduction of forefoot plantar pressure through foot orthoses is a common treatment for these conditions and for non-specific metatarsalgia. Moreover, forefoot pain is one of the most common foot complaints for which foot orthoses are prescribed[2]. Several studies have shown effectiveness of foot orthoses and/or inserts on pressure reduction in patients with metatarsalgia [3-10], but there seems to be considerable variation for different aspects of orthoses therapy such as prescription habits [11-14], foot examination [15-22] and casting[23]. No publications on the evaluation of different professional groups are available as far as plantar pressure management is concerned.

Dutch medical specialists and general practitioners prescribe foot orthoses which are mainly provided by podiatrists, pedorthists (orthopaedic shoemaker) and orthotists (orthopaedic technician). These disciplines have separate vocational training. They differ regarding diagnostic procedures, construction of orthoses and therapeutic approach e.g.: pedorthists are specialized in foot orthosis therapy for orthopaedic shoe wear, whereas podiatrists and orthotists mainly provide foot orthoses for nonorthopaedic shoe wear. In general, orthotists take care of more severe disorders than podiatrists[14]. Although each discipline has a specific focus on particular foot problems, all three disciplines provide foot orthoses for comfort shoes to treat foot impairments associated with elevated plantar forefoot peak pressures: e.g. higher than 700 $\mathrm{kPa}[24,25]$. It is not known what the consequences of these differences are for the extent of pressure reduction. The purpose of this study was to evaluate the effect of custom-made foot orthoses, made by representatives of these professional groups in the Netherlands, on forefoot plantar pressure and walking convenience. Three patients with metatarsalgia and elevated forefoot plantar pressure were chosen as examples to show the effects of the orthoses. The specific aims were to assess possible differences in plantar pressure reduction in these patients between the professional groups, its variability within the groups and the differences of that variability between the three groups. In addition, the relationship between the importance of pressure reduction as stated by the therapist and the effect on plantar peak pressure through foot orthoses was evaluated.

\section{Methods \\ Therapists}

As representatives of their professional groups, ten podiatrists, ten pedorthists and eleven orthotists from the southern part of The Netherlands were asked to construct foot orthoses for three patients with metatarsalgia and ele- vated forefoot peak pressure. Podiatrists were approached through telephone directories. Companies of pedorthists and orthotic workshops were approached through member lists of the professional associations. Each delegated between one and three therapists for the study. The median professional experience in years was $7.5 ; 16.5$ and 20 , respectively for podiatrists, pedorthists and orthotists.

\section{Patients}

Three patients, 2 females of 60 and 61 years old and a 37 years old male, with forefoot complaints, elevated plantar peak pressures and an indication for foot orthoses were selected from an orthopaedic outpatient clinic. The male patient had foot problems related to psoriatic arthritis, which was inactive during the study period. The specific diagnosis for both female patients was bilateral metatarsalgia due to overloading of the forefoot as consequence of structural defects (table 1) leading to functional anomalies. Additional details about the patients are given in table 1 . Before the start of the study, patients were informed about all study procedures and their possible risks. The Research Ethical Committee of the University Hospital Maastricht approved the study.

\section{Casting and construction of foot orthoses}

Two sessions were organised at the University Hospital Maastricht with an interval of three weeks between sessions. The first session included patient examination and casting. Therapists were asked to rate the 'importance of pressure reduction' per patient through line bisection of a 100 millimetre visual analogue scale. The orthoses were constructed in the three weeks between the sessions. During the second session, before final delivery, the therapists had an opportunity to check the constructed orthoses for adequacy. If deemed necessary, accommodations of orthoses were made.

\section{Inshoe plantar pressure measurement and evaluation of foot orthoses}

Per patient 31 pairs of foot orthoses were evaluated twice in two sessions. Two pairs of sham orthoses were added to create eleven blocks of three pair of orthoses, one from each discipline. The blocks were randomized to determine the measurement sequence and this sequence was reversed for the second session. All orthoses were evaluated in the patient's own shoes and wearing standard thin socks while walking on a treadmill. The Pedar Insole-system $^{\circledast}$ (Novel, Munich) was used to measure plantar pressures[26,27]. The first author performed all measurements. Whether these off the shelf shoes had enough space for adding orthoses and the Pedar insole was checked. Patients individually chose their preferred walking speed (table 1), which was kept the same for all subsequent measurements. To minimize a possible effect of the test sequence, such as a possible effect of fatigue on 
Table I: Patient characteristics

\begin{tabular}{|c|c|c|c|c|c|c|}
\hline Patient & \multicolumn{2}{|c|}{$\mathbf{A}$} & \multicolumn{2}{|c|}{ B } & \multicolumn{2}{|c|}{ C } \\
\hline Gender & \multicolumn{2}{|c|}{ female } & \multicolumn{2}{|c|}{ female } & \multicolumn{2}{|c|}{ male } \\
\hline Age $(y r)$ & \multicolumn{2}{|c|}{60} & \multicolumn{2}{|c|}{61} & \multicolumn{2}{|c|}{37} \\
\hline Weight $(\mathrm{kg})$ & \multicolumn{2}{|c|}{105} & \multicolumn{2}{|c|}{73} & \multicolumn{2}{|c|}{82} \\
\hline Body length $(\mathrm{cm})$ & \multicolumn{2}{|c|}{178} & \multicolumn{2}{|c|}{154} & \multicolumn{2}{|c|}{181} \\
\hline Preferred walking speed $\left(\mathrm{m} \cdot \mathrm{s}^{-1}\right)$ & \multicolumn{2}{|c|}{1,63} & \multicolumn{2}{|c|}{0,88} & \multicolumn{2}{|c|}{1,72} \\
\hline \multirow[t]{2}{*}{ Systemic diseases } & & & & & \multicolumn{2}{|c|}{ Arthritis psoriatica } \\
\hline & left & right & left & right & left & right \\
\hline \multicolumn{7}{|l|}{ Structural classification } \\
\hline pes plano valgus & $\mathbf{x}$ & $\mathbf{x}$ & & & & \\
\hline calcaneus valgus & & & & & $\mathbf{x}$ & $\mathbf{x}$ \\
\hline hallux valgus & & & $\mathbf{x}$ & $\mathbf{x}$ & & \\
\hline bunion & & & $\mathbf{x}$ & $\mathbf{x}$ & & \\
\hline claw toes & & & & & $\mathbf{x}$ & $\mathbf{x}$ \\
\hline \multicolumn{7}{|l|}{ Specific diagnosis } \\
\hline Metatarsalgia & $\mathbf{x}$ & $\mathbf{x}$ & $\mathbf{x}$ & $\mathbf{x}$ & $\mathbf{x}$ & $\mathbf{x}$ \\
\hline Plantar fasciitis & & $x$ & & & & \\
\hline MTP-I joint Extension & $50^{\circ}$ & $50^{\circ}$ & $50^{\circ}$ & $35^{\circ}$ & $55^{\circ}$ & $60^{\circ}$ \\
\hline MTP-I joint Flexion & $45^{\circ}$ & $40^{\circ}$ & $30^{\circ}$ & $35^{\circ}$ & 400 & $45^{\circ}$ \\
\hline *Bare foot peak pressure $(\mathrm{kPa})$ & 907 & 506 & 771 & 662 & 1202 & 826 \\
\hline
\end{tabular}

$\mathrm{Yr}=$ years, $\mathrm{kg}=$ kilogram, $\mathrm{cm}=$ centimetre, $\mathrm{m}=$ metre, $\mathrm{s}=$ second,

MTP = metatarsophalangeal, *highest value under the plantar forefoot is showed.

plantar pressures, an equal number of steps from both sessions were used for evaluation. Data were recorded for approximately 50 seconds with a frequency of 50 frames per second. Plantar peak pressure was estimated by calculating the mean over the readings of 40 steps (20 steps per session). This was done for six separate regions: big toe (BT) and metatarsal one (mt-1) to five (mt-5) through anterior-posterior radiographs and Novel 'create any mask $^{\otimes 1}$ software[28]. Baseline values of inshoe plantar pressures, i.e. without orthoses, were calculated as the mean of 4 measurements: for each session, one before and one at the end of the test series. In order to check the influence of fatigue on peak pressure, we compared the before and after values without orthoses of each test session. After each measurement, patients scored walking convenience for left and right orthosis on a ten-point scale on a questionnaire: How do you rate the walking convenience of these orthoses $(0=$ extremely bad, $10=$ excellent $)$ ? Walking convenience was estimated by calculating the mean score of the two sessions.

\section{Analysis}

Differences in plantar pressure reduction amongst the professional groups were evaluated for the region with the highest peak pressure measured under the forefoot without orthosis (table 2). For patient B and C the effect on peak pressure was also evaluated for their right and left BT regions respectively, because pressures in these regions were high compared to the peak pressures under the met- atarsals. At first plantar pressure data were investigated for normal distribution by the Kolmogorov-Smirnov test. If the data did not meet the assumptions for parametric analysis, a Friedman test was used for non-parametric overall analysis. If there was a statistically significant difference between the groups, Wilcoxon Signed Ranks Tests were performed for pair-wise comparison. We also evaluated the effect of the orthoses focusing on the region were the peak pressure reduction was maximal. For this, the difference between the peak pressure measured with orthoses and the baseline value was calculated for each forefoot region. The largest difference was used for this evaluation.

Variance of the maximal pressure reduction was used to show the within-group variation and to test for equality of these within group variations between the three disciplines. For this purpose a homogeneity of variance analysis was performed with a repeated measures ANOVA, using the GENOVA computer program[29].

For the assessment of the relationship between achieved pressure reduction and 'importance of pressure reduction' we used the maximal pressure reduction. For this purpose linear regression analysis was performed for the cases were there was a wide distribution of the 'importance of pressure reduction' ratings. Statistical analysis was carried out with SPSS $12.01^{\circledast}$ software (SPSS Inc.). An alpha level of 0.05 was chosen to judge statistical significance. 
Table 2: Baseline inshoe peak pressures (kiloPascal).

\begin{tabular}{|c|c|c|c|c|c|c|}
\hline & A left & A right & B left & B right & C left & C right \\
\hline BT & 208 & 200 & 204 & 298 & 466 & 200 \\
\hline mt-I & 359 & 378 & 250 & 258 & 234 & 147 \\
\hline mt-2 & 429 & 358 & 218 & 249 & 292 & 291 \\
\hline mt-3 & 428 & 270 & 332 & 280 & 336 & 332 \\
\hline mt-4 & 237 & 226 & 266 & 219 & 207 & 307 \\
\hline mt-5 & 214 & 173 & 200 & 174 & 69 & 200 \\
\hline
\end{tabular}

Highest baseline inshoe peak pressures for $\mathrm{mt}$ regions are bold printed. For patient B \& C, BT regions were added because of high local peak pressures.

$\mathrm{BT}=$ big toe, $\mathrm{mt}=$ metatarsal

\section{Results}

\section{Description of constructed orthoses}

Orthoses made by podiatrists clearly differ from orthoses from pedorthists and orthotists. All podiatrists constructed thin insoles out of rubber, leather and cork, but they varied in the application of corrective and/or supportive elements. In broad outlines, orthoses of pedorthists and orthotists were similar. The pedorthists and orthotists made orthoses that look more like the 'Root style' orthoses[14,30]. However, within the professional groups, there was a considerable variation in applied materials and the use of corrective and supportive adaptations. All orthoses from podiatrists were fully custommade while this was only the case for $56 \%$ of orthoses from pedorthists and $45 \%$ of those from orthotists. The remainder were partly or completely constructed from prefabricated elements. Podiatrists constructed full-length orthoses for all patients. Pedorthists provided 34\% fulllength orthoses, 20\% three-quarter and 46\% 'in between' length orthoses. Orthotists provided 58\% full-length orthoses, $24 \%$ three-quarter and $18 \%$ 'in between' length orthoses.

\section{Plantar pressure measurements}

For all three patients, the changes of the plantar pressure measurements without orthoses, from before to after the test series, were very small. The change during session 1 for patient A was 0.4 , patient B -4.5 , patient $C 5.1 \mathrm{kPa}$. During session 2: patient A -0.3 , patient $\mathrm{B}-4.3$, patient $\mathrm{C}$ $-2.1 \mathrm{kPa}$. We concluded that there was no relevant effect of fatigue on peak pressures in the course of the measurement sessions.

Effect of orthoses on highest pressure regions for patient $A$ Results for each region for pair wise statistical testing are listed in the figure 1 . The highest baseline peak pressures for patient A were measured in the left mt-2 and the right mt-1 regions (table 2). With respect to the left $\mathrm{mt}-2$ region, orthotists and pedorthists achieved greater median reductions, $117 \mathrm{kPa}$ and $71 \mathrm{kPa}$, than podiatrists, $13 \mathrm{kPa}: \mathrm{p}=.022$. For the right $\mathrm{mt}-1$ region, both orthotists and pedorthists achieved a greater median reduction of 54
$\mathrm{kPa}$, while the orthoses of podiatrists resulted in an increase of peak pressure by $50 \mathrm{kPa}$. The differences between orthotists and pedorthists compared to podiatrists were statistically significant: $\mathrm{p}=.021$.

\section{Effect of orthoses on highest pressure regions for patient $B$} The highest baseline peak pressures for patient $\mathrm{B}$ were measured in both mt-3 regions (table 2). Orthotists, pedorthists, and podiatrists achieved median reductions of 93, 91 and $58 \mathrm{kPa}$ respectively: figure 1 . For the right mt-3 region, these reductions were 57, 24 and $43 \mathrm{kPa}$ respectively. The difference between orthotists and pedorthists was statistically significant: $\mathrm{p}=.019$ (figure 1).

\section{Effect of orthoses on highest pressure regions for patient $C$} The highest baseline peak pressures for patient $C$ were also measured in both mt-3 regions (table 2). Orthoses of pedorthists, orthotists and podiatrists achieved a median reduction of 149,141 and $136 \mathrm{kPa}$ respectively in the left mt-3 region (figure 1 ). For the right mt-3 region, these reductions were 89,83 and $65 \mathrm{kPa}$ respectively (figure 1 ).

\section{Effect of orthoses on highest pressure in big toe regions of patient $B$ and $C$}

For patient $\mathrm{B}$ and $\mathrm{C}$, a high peak pressure was measured in the corresponding right and left BT region (table 2). Orthoses of pedorthists, orthotists and podiatrists achieved a median reduction of 46,44 and $3 \mathrm{kPa}$ respectively, in the right $\mathrm{BT}$ region of patient $\mathrm{B}$ (figure 1 ). For the left BT region of patient $\mathrm{C}$, orthoses of orthotists, podiatrists and pedorthists achieved a median reduction of respectively 162, 160 and $120 \mathrm{kPa}$ (figure 1).

\section{Within group variances of maximal peak pressure reduction}

The maximal reduction of peak pressure calculated for the whole plantar surface over all forefeet was greater with orthoses of pedorthists $(\mathrm{p}=.005)$ and orthotists $(\mathrm{p}<$ $.001)$ than orthoses of podiatrists: -96 and -102 versus -75 $\mathrm{kPa}$ respectively. The within-group variability, expressed as standard deviation, of the maximal local peak pressure reduction for the whole forefoot were 16.0, 14.2 and 16.3 


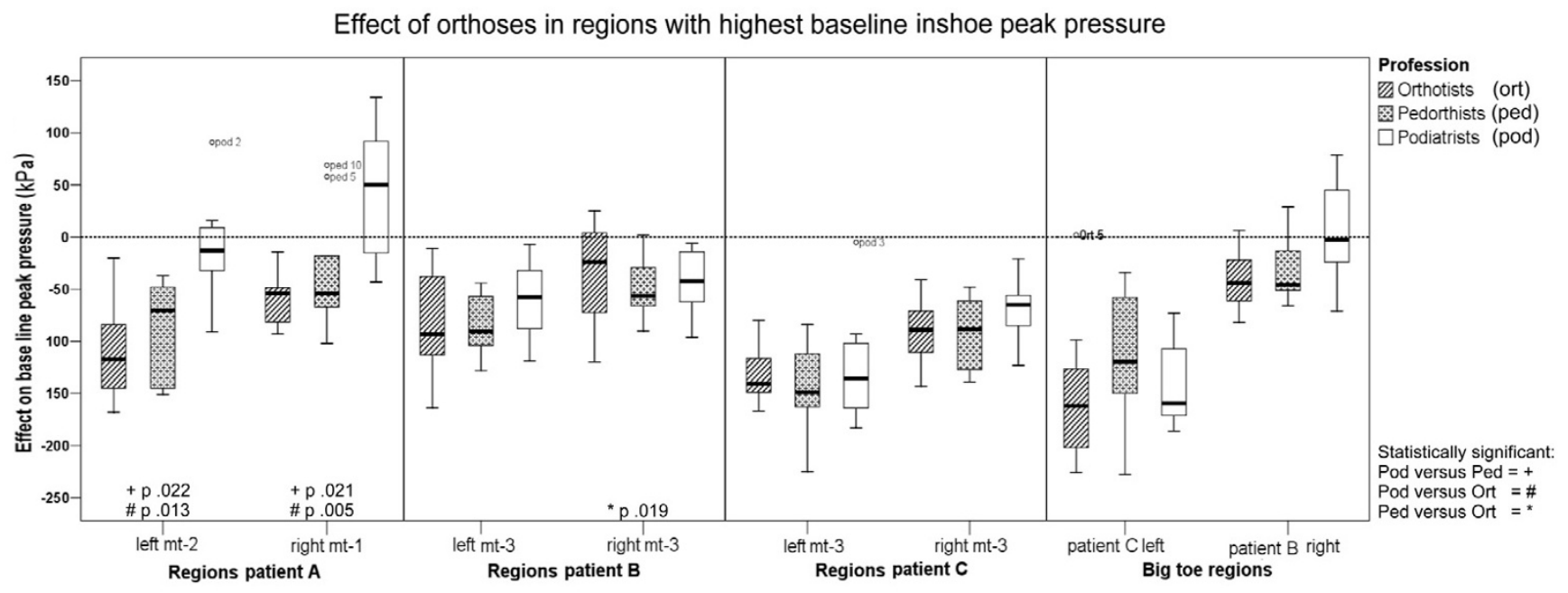

Figure I

The effect of orthoses in regions with the highest baseline inshoe peak pressure. Boxplots show the median, interquartile range, outliers (o), and extreme cases $(*)$ of individual variables.

$\mathrm{kPa}$ for podiatrists, pedorthists and orthotists respectively (table 3). The differences of the within-group variances between the disciplines were not statistically significant.

\section{The relationship between the 'importance of pressure reduction' and the effect on peak pressure}

Box and whisker plots show the median scores and quartiles for 'importance of pressure reduction' rated by the therapists (figure 2). The median ratings by podiatrists for patients A, B and C were respectively: 68, 65 and 81 out of $100 \mathrm{~mm}$. The ratings by pedorthists for patients A, B and $\mathrm{C}$ were 88,86 and $93 \mathrm{~mm}$, respectively. The ratings by orthotists for patients A, B and C were 90,81 and $93 \mathrm{~mm}$ respectively.

The relationship between the 'importance of pressure reduction' and the effect on peak pressure for the whole forefoot was only evaluated for patients for which therapists within professional groups had a large variation in their judgement of the importance of pressure reduction: for podiatrists patients A and B and for orthotists patient B (figure 3).

Linear regression analysis showed only statistically significant weak negative associations between the 'importance of pressure reduction' ratings by orthotists and the effect on peak pressure for the left and right foot of patient $B$. Importance of pressure reduction explained 50\% ( $\mathrm{p}=$ $.015)$ and $48 \%(p=.019)$ of the variance of the effect on peak pressure, respectively (figure 3 ). There was no statis- tically significant relation between ratings of podiatrists and effect on peak pressure for patient A and B.

Podiatrists had less years of professional experience than pedorthists $(\mathrm{p}=.037)$ and orthotists $(\mathrm{p}=.008)$, while orthotists and pedorthists did not differ in years professional experience. Multiple regression analysis showed that there was no, or a very weak, relationship between achieved pressure reduction and years professional experience, number of constructed orthoses per week, or importance of pressure reduction (data not shown).

The appreciation of walking convenience by the patients is shown in table 4 (Means were calculated through the mean of two ratings per therapist). Walking convenience was better rated by patients $A$ and $B$ for orthoses of pedorthists and orthotists compared to orthoses of podiatrists. The differences for both feet of patient B were statistically significant (left: $\mathrm{p}=.005$, right: $\mathrm{p}=.005$ ). For patient $\mathrm{A}$, only the differences between orthotists and podiatrists for both feet were statistically significant (left: $\mathrm{p}=.019$, right: $\mathrm{p}=.047)$. According to the ratings of patient $\mathrm{C}$, pedorthists scored, on average, better than podiatrists and podiatrists better than orthotists.

\section{Discussion}

We studied the effect of 186 custom-made foot orthoses (31 therapists, 3 patients, 2 feet) made by podiatrists, pedorthists and orthotists on plantar pressure and walking convenience for three patients with elevated forefoot 
Table 3: Maximal peak pressure reduction calculated for the total plantar surface of all forefeet (kiloPascal).

\begin{tabular}{rccc}
\hline & Mean reduction & SD & Minimum-Maximum \\
\hline Podiatrists & -75 & 16.0 & $-186: 4$ \\
Pedorthists & -96 & 14.2 & $-226:-15$ \\
Orthotists & -102 & 16.3 & $-228:-18$ \\
\hline
\end{tabular}

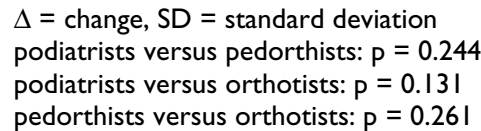

peak pressures and metatarsalgia. Within the three disciplines there was a large variation in construction of the orthoses and achieved peak pressure reductions. On average, the pedorthists and orthotists achieved slightly greater pressure reductions and a better walking convenience than podiatrists.

In accordance with what was reported in other studies, it turned out to be impossible to categorize the constructed orthoses in general orthotic classifications, such as 'functional' or 'accommodative'[11]. Therefore, we only described aspects of the shape of the orthoses and the materials used. Generally speaking, the orthoses made by pedorthists and orthotists were similar to orthoses of Anglo-Saxon podiatrists, although, rigorous application of procedures for casting and construction of functional

\section{Importance of pressure reduction}

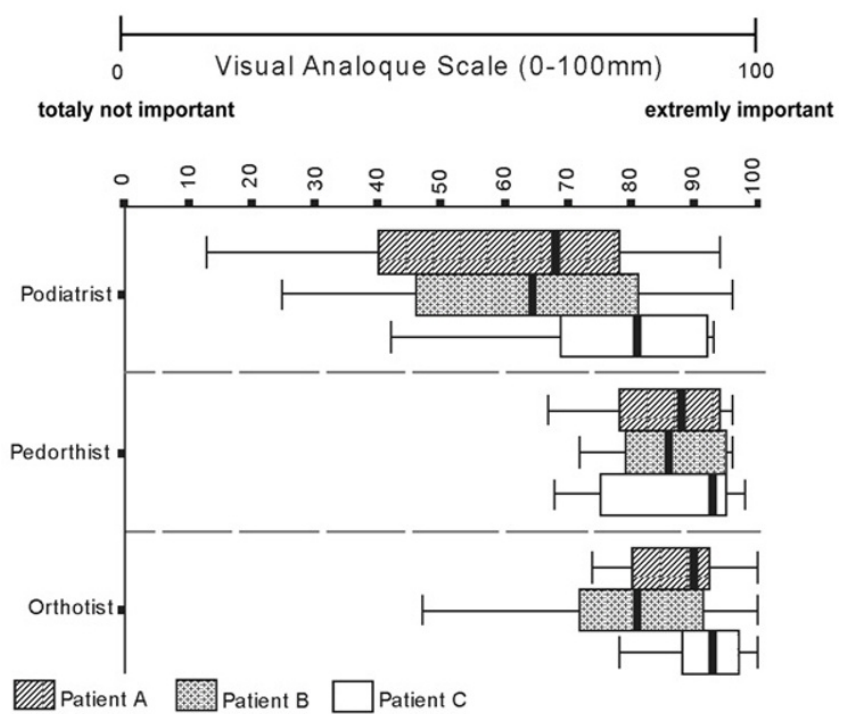

Figure 2

Importance of pressure reduction (quartiles). Zero millimetre indicates totally not important and 100 millimetre indicates extremely important. Boxplots show the median and interquartile range. orthoses according to the American College of Foot \& Ankle Orthopaedics \& Medicine (ACFAOM) and the Australian Podiatry Council practice guidelines[31,32], were not commonly used. Orthoses of podiatrists were constructed according to the principles described by Lelièvre[33] and further developed by Lavigne and associates [34-36]. They were based on pressure sheet and physical examination and constructed as a thin sole with delicate corrective and/or supportive elements made from leather, rubber and cork. The Dutch podiatric orthoses are different from the custom-made foot orthoses made by the Anglo-Saxon podiatrists, which are usually constructed according to the concepts formulated by Root et al $[11,16,30,37,38]$.

Importance of pressure reduction \& effect on peak pressure

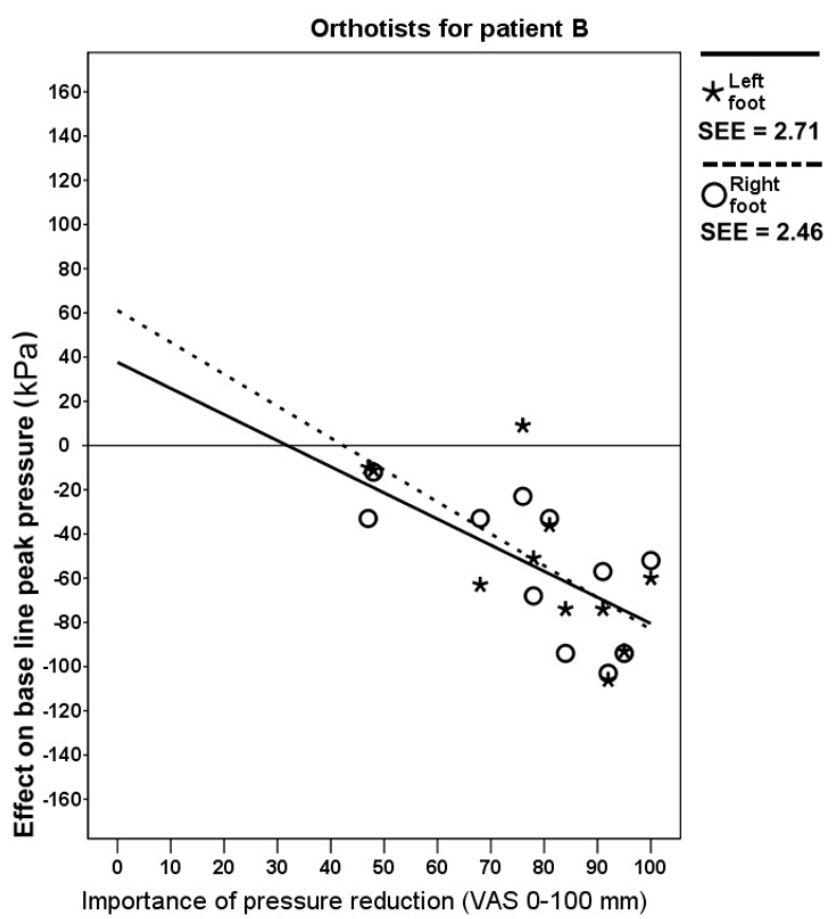

Figure 3

Importance of pressure reduction rated by orthotists for patient B \& effect on peak pressure. SEE = standard error of the estimate. 
Table 4: Mean effects of orthoses on walking convenience (10-point scale)

\begin{tabular}{lcccccc}
\hline & \multicolumn{2}{c}{ Patient A } & \multicolumn{2}{c}{ Patient B } & \multicolumn{2}{c}{ Patient C } \\
& Left & Right & Left & Right & Left & Right \\
\hline Podiatrist & $6.5 \pm 0.3$ & $6.5 \pm 0.6$ & $4.0 \pm 0.4$ & $4.0 \pm 0.4$ & $4.8 \pm 1.3$ & $5.0 \pm 0.9$ \\
Pedorthist & $7.5 \pm 1.1$ & $7.5 \pm 0.8$ & $7.0 \pm 1.0$ & $7.0 \pm 1.0$ & $5.0 \pm 1.6$ & $5.3 \pm 1.3$ \\
Orthotist & $7.5 \pm 0.8$ & $7.5 \pm 0.7$ & $6.5 \pm 1.0$ & $6.5 \pm 1.0$ & $4.5 \pm 1.3$ & $4.5 \pm 1.3$ \\
\hline
\end{tabular}

Walking convenience scale $0-10$ points $(0=$ extremely bad, $10=$ excellent). Means were calculated through the mean of two ratings per therapist, $( \pm \ldots)=$. standard deviation.

We assessed the pressure reduction effect of orthoses for the region with the largest peak pressure. This is where the largest effects should be achieved. In general, pedorthists and orthotists achieve greater reductions, than podiatrists. However, these differences in peak pressure reductions between podiatrists versus pedorthists and orthotists were statistically significant for only one of the patients. In addition, the maximal local reduction of peak pressure calculated for the whole plantar surface over all forefeet was statistically significantly greater with orthoses of pedorthists and orthotists than orthoses of podiatrists.

In one of the patients, at the location of the highest baseline peak pressure, the podiatric orthoses even resulted in a increase of the peak pressure. Such an increase of plantar pressure could be dangerous, especially in neuropathic feet[39,40].

According to the ratings for 'importance of pressure reduction', optimizing pressure distribution was a main treatment goal for most therapists (figure 2). However, there was no relationship for podiatrists and a weak relationship for orthotists (figure 3) between the supposed 'importance of pressure reduction' and the achieved pressure reduction. This implies that there is a discrepancy between treatment goal and treatment effect with respect to plantar pressure reduction. This is worrisome because optimizing pressure distribution is an important aim of foot orthoses therapy [25].

Walking convenience is important for the patient's preference and acceptance of an orthosis for daily use. Two patients scored walking convenience better for orthoses of pedorthists and orthotists compared to orthoses of podiatrists. For patient $C$ there were no clear differences. However, because walking convenience was judged immediately after the measurement session, it remains unclear whether the patient's preference will stay the same after getting used to the orthosis.

The general theoretical and practical concepts of foot orthoses therapy should be common to the therapists of each discipline concerned. The situation in the Netherlands for establishing this professional uniformity is optimal because there is only one school for each discipline.
Nevertheless, there is a large variation in orthoses construction and treatment effects within each discipline, while there were no differences in the variation in effect on peak pressure among the three disciplines.

We evaluated the effects of foot orthoses therapy on plantar pressure and walking convenience for only three patients. We did not set out to examine patient-specific therapy outcome. Although the effects of orthoses for patients with other foot pathologies and plantar pressure patterns could be different, we see no reasons why the differences between the professional groups and the variation within professional groups would be substantially different for other patients. We are of the opinion that the therapists who participated in our study are a fair representation of their national colleagues. There could even be some underestimation of the variation within professional groups because some of the therapists work within the same company.

Variation in plantar pressure management could be the result of inconsistent application of diagnostic procedures, of setting treatment goals and methods of constructing orthoses. In a previous study we indeed showed that therapists often disagree about the locations with high plantar pressures[41]. Information about variability of clinical achievements among therapists is essential for the interpretation of the results of studies where foot orthoses therapy is evaluated $[42,43]$. Only when there is a small variation is it possible to extrapolate the effect of therapy achieved by one therapist to his or her colleagues.

We showed a large variation among therapists for the Dutch situation. It is difficult to say whether these results can be generalised to professional groups in other countries. However, we do not know of any study showing that the situation is better elsewhere. Insofar as variation has been studied, specific aspects like diagnostic procedures and orthoses prescription show similar variability problems $[11,23,44-52]$.

\section{Conclusion}

This study showed differences between three disciplines that construct custom foot orthoses for patients in The Netherlands with respect to construction, presumed 
importance of plantar pressure reduction, achieved pressure reduction and walking convenience. On average, pedorthists and orthotists achieved a slightly larger pressure reduction in high peak pressure regions and a better walking convenience than podiatrists did. There was a weak relationship between the importance of pressure reduction' and the achieved pressure reduction for orthotists, but no relationship for podiatrists and orthotists. The large variation in construction of the orthoses and in peak pressure reduction within the professional groups raises questions about a consistent application of therapeutic concepts for the management of elevated peak pressures.

A better understanding of and consensus about the mechanisms underpinning the effectiveness of foot orthoses therapy is needed in order to improve foot orthoses therapy, This must lead to unambiguous guidelines that enable improved education and consequently less variation between therapists.

\section{Competing interests}

The author(s) declare that they have no competing interests.

\section{Authors' contributions}

All authors designed the study. NG collected and prepared the data. NG, PL and FN analyzed the data. All authors interpreted and discussed the data. NG, PL and GW drafted the manuscript. NA and PL revised the manuscript. All authors read and approved the final manuscript.

\section{Acknowledgements}

This study was supported by The Netherlands Organisation for Health Research and Development (ZonMw) and the Dutch Diabetes Research Foundation. We thank all patients and therapists who participated in this study.

\section{References}

I. Bardelli M, Turelli L, Scoccianti G: Definition and classification of metatarsalgia. J Foot Ankle Surg 2003, 9:79-85.

2. Poon C, Love B: Efficacy of foot orthosis for metatarsalgia. The Foot 1999.

3. Ivanic GM, Trnka H], Homann NC: [Post-traumatic metatarsalgia. Early results of treatment with a new insole]. Unfallchirurg 2000, 103:507-510.

4. Hodge MC, Bach TM, Carter GM: novel Award First Prize Paper. Orthotic management of plantar pressure and pain in rheumatoid arthritis. Clin Biomech (Bristol, Avon) 1999, I 4:567-575.

5. Chang AH, Abu-Faraj ZU, Harris GF, Nery J, Shereff MJ: Multistep measurement of plantar pressure alterations using metatarsal pads. Foot Ankle Int 1994, I 5:654-660.

6. Woodburn J, Barker S, Helliwell PS: A randomized controlled trial of foot orthoses in rheumatoid arthritis. J Rheumatol 2002, 29:1377-1383.

7. Novick A, Stone J, Birke JA, Brasseaux DM, Broussard JB, Hoard AS, Hawkins ES: Reduction of plantar pressure with the rigid relief orthosis. J Am Podiatr Med Assoc 1993, 83: I I5-I22.

8. Bitzan P, Giurea A, Wanivenhaus A: Plantar pressure distribution after resection of the metatarsal heads in rheumatoid arthritis. Foot Ankle Int 1997, 18:39|-397.
9. Jackson L, Binning J, Potter J: Plantar pressures in rheumatoid arthritis using prefabricated metatarsal padding. J Am Podiatr Med Assoc 2004, 94:239-245.

10. Kavlak Y, Uygur F, Korkmaz C, Bek N: Outcome of orthoses intervention in the rheumatoid foot. Foot Ankle Int 2003, 24:494-499.

I I. Landorf K, Keenan AM, Rushworth RL: Foot orthosis prescription habits of Australian and New Zealand podiatric physicians. J Am Podiatr Med Assoc 200I, 91: 174- I83.

12. Boer H, Seydel ER: Medical opinions, beliefs and prescription of orthopaedic footwear: a survey of Dutch orthopaedists and rehabilitation practitioners. Clin Rehabil 1998, I 2:245-253.

13. Morris C, Newdick H, Johnson A: Variations in the orthotic management of cerebral palsy. Child Care Health Dev 2002, 28:|39-| 47

14. Bakker JP, De Groot IJ, De Jong BA, Van Tol-De Jager MA, Lankhorst G]: Prescription pattern for orthoses in The Netherlands: use and experience in the ambulatory phase of Duchenne muscular dystrophy. Disabil Rehabil 1997, 19:318-325.

15. Hopson MM, McPoil TG, Cornwall MW: Motion of the first metatarsophalangeal joint. Reliability and validity of four measurement techniques. J Am Podiatr Med Assoc 1995, 85: 198-204.

16. Ball P, Johnson GR: Technique for the measurement of hindfoot inversion and eversion and its use to study a normal population. Clin Biomech (Bristol, Avon) 1996, I I:165-169.

17. Elveru RA, Rothstein JM, Lamb RL: Goniometric reliability in a clinical setting. Subtalar and ankle joint measurements. Phys Ther 1988, 68:672-677.

18. Buckley RE, Hunt DV: Reliability of clinical measurement of subtalar joint movement. Foot Ankle Int 1997, 18:229-232.

19. Menz HB, Tiedemann A, Kwan MM, Latt MD, Sherrington C, Lord SR: Reliability of clinical tests of foot and ankle characteristics in older people. J Am Podiatr Med Assoc 2003, 93:380-387.

20. Thompson L, Nester C, Stuart L, Wiles P: Interclinician variation in diabetes foot assessment - a national lottery? Diabet Med 2005, 22(2): 196-199.

21. Thompson L, Nester C, Stuart L, Wiles P: Interclinician variation in diabetes foot assessment--a national lottery? Diabet Med 2005, 22:196-199.

22. Pierrynowski MR, Smith SB: Rear foot inversion/eversion during gait relative to the subtalar joint neutral position. Foot Ankle Int 1996, 17:406-4I2.

23. Pierrynowski MR, Smith SB: Effect of patient position on the consistency of placing the rearfoot at subtalar neutral. J Am Podiatr Med Assoc 1997, 87:399-406.

24. Chuter V, Payne C, Miller K: Variability of neutral-position casting of the foot. J Am Podiatr Med Assoc 2003, 93:1-5.

25. Zuijderduin WM, Dekker J: Diagnoses and interventions in podiatry. Disability and Rehabilitation 1996, 18:27-34.

26. Kruizinga CP, Boonstra A, Groothoff JW, Elzinga A, Goeken NLH Characteristics of patients supplied with foot orthoses from orthopaedic workshops in The Netherlands. The Foot 2003, 13:39-45.

27. Kernozek TW, LaMott EE, Dancisak MJ: Reliability of an in-shoe pressure measurement system during treadmill walking. Foot Ankle Int 1996, 17:204-209.

28. Boyd LA, Bontrager EL, Sara MS, Perry J: The reliability and validity of the Novel Pedar system of in-shoe pressure measurement duringfree ambulation. Gait \& Posture 1997, 5:165.

29. Weijers RE, Walenkamp GHIM, Mameren van H, Kessels AG: The relationship of the position of the metatarsal heads and peak plantar pressure. Foot and Ankle Int 2003, 24:349-353.

30. Crick JE, Brennan RL: GENOVA: a GENeral purpose analysis Of VAriance system. version 2.2.1984.

31. Root ML: Development of the functional orthosis. Clin Podiatr Med Surg 1994, I I:I83-210.

32. Bernard MA, Goldsmith $\mathrm{H}$, Curnick KL, Jarret B: Prescription of custom foot orthoses practice guidelines. Ellicott City, MD 2 1043-4547, The American College Of Foot And Ankle Orthopedics \& Medicine; $2002: 32$

33. Price J: Clinical guidelines for orthotic therapy provided by podiatrists. 4I Derby Street, Collingwood Vic 3066 AUS, Australian Podiatry Council; 1998.

34. Lelièvre J, Lelièvre JF: Pathologie du Pied. 5ème ed. edition. Paris, Masson éditeur; 1981. 
35. Martorell Martorell J: Nouvelle semelle pour métatarsalgie. Podologie 1968, 6:419.

36. Lavigne A, Noviel D: Nouvelles thérapeutiques en podologie. Paris, Morgan; 1973

37. Lavigne $A$, Noviel $D$ : Traite théorique et pratique de la semelle orthopédique. Boulogne, Scerdes; 1975.

38. Moraros J, Hodge W: Orthotic survey. Preliminary results. J Am Podiatr Med Assoc 1993, 83:139-148.

39. Root ML, Orien WP, Weed JH: Normal and abnormal function of the foot. Los Angeles CA., Clinical Biomechanics Corporation Publishers; 1977.

40. Armstrong DG, Liswood PJ, Todd WF: Potential risks of accommodative padding in the treatment of neuropathic ulcerations. Ostomy Wound Manage 1995, 41:44-6, 48-9.

4I. Martin N, Oldani T, Claxton MJ: A Guide To Offloading The Diabetic Foot. Podiatry Today 2005, 18:67-74.

42. Guldemond NA, Leffers P, Sanders AP, Schaper NC, Walenkamp GHIM: Clinical proficiency of Dutch podiatrists, pedorthists and orthotists regarding plantar pressure reduction [Abstract], Novel EMED scientific meeting 2004, Leeds UK. Clin Biomech (Bristol, Avon) 2005, 20:SI 4

43. Pratt DJ: A critical review of the literature on foot orthoses. J Am Podiatr Med Assoc 2000, 90:339-34I.

44. Spencer S: Pressure relieving intervention for preventing and treating diabetic foot ulcers (Cochrane Review). Oxford, The Cochrane Library; 200I:I4.

45. Dahle LK, Michael MJ: Visual assessment of foot type and relationship of foot type to lower extremity injury. Journal of Orthopaedic \& Sports Physical Therapy 1991, 14:70-74.

46. Cornwall MW, McPoil TG: Footwear and foot orthotic effectiveness research: a new approach. J Orthop Sports Phys Ther 1995, $21: 337-344$

47. Landorf KB, Keenan AM: Efficacy of foot orthoses: What does the literature tell us? J Am Podiatr Med Assoc 2000, 90:149-I58

48. Pierrynowski MR, Smith SB, Mlynarczyk JH: Proficiency of foot care specialists to place the rearfoot at subtalar neutral. J Am Podiatr Med Assoc 1996, 86:217-223.

49. Payne $C B$ : The past, present, and future of podiatric biomechanics. J Am Podiatr Med Assoc 1998, 88:53-63.

50. Laughton C, McClay Davis I, Williams DS: A comparison of four methods of obtaining a negative impression of the foot. J Am Podiatr Med Assoc 2002, 92:261-268.

51. Lee WE: Podiatric biomechanics. An historical appraisal and discussion of the Root model as a clinical system of approach in the present context of theoretical uncertainty. Clin Podiat Med Surg 200I, I8:555-684; discussion 685-90, v.

52. Miller M, McGuire J: Literature reveals no consensus on subtalar neutral. Biomechanics 2000, 7:63-74.

53. Elveru RA, Rothstein JM, Lamb RL, Riddle DL: Methods for taking subtalar joint measurements. A clinical report. Phys Ther 1988, 68:678-682.

\section{Pre-publication history}

The pre-publication history for this paper can be accessed here:

http://www.biomedcentral.com/1471-2474/6/61/prepub
Publish with Biomed Central and every scientist can read your work free of charge

"BioMed Central will be the most significant development for disseminating the results of biomedical research in our lifetime. "

Sir Paul Nurse, Cancer Research UK

Your research papers will be:

- available free of charge to the entire biomedical community

- peer reviewed and published immediately upon acceptance

- cited in PubMed and archived on PubMed Central

- yours - you keep the copyright
BioMedcentral 